\title{
Association of influenza epidemics with global climate variability
}

\author{
Cécile Viboud ${ }^{1,2}$, Khashayar Pakdaman ${ }^{1}$, Pierre-Yves Boëlle ${ }^{1}$, Mark L. Wilson ${ }^{3}$, \\ Monica F. Myers ${ }^{4}$, Alain-Jacques Valleron ${ }^{1} \&$ Antoine Flahault ${ }^{1,2}$ \\ ${ }^{1}$ Institut National de la Santé et de la Recherche Médicale, Unit 444, Epidemiology and Information Sciences, Centre \\ Hospitalo-Universitaire Saint-Antoine; ${ }^{2}$ WHO Collaborating Center for electronic disease surveillance, 27 rue Chaligny, \\ 75571 Paris cedex 12, France; ${ }^{3}$ University of Michigan, Department of Epidemiology, 109 S. Observatory Street, \\ Ann Arbor, MI 48109-2029, USA; ${ }^{4}$ Human Health Initiative, NASA Goddard Space Flight Center, Code 902, Greenbelt, \\ MD 20770, USA
}

Accepted in revised form 12 August 2004

\begin{abstract}
The reasons for the seasonality and annual changes in the impact of influenza epidemics remain poorly understood. We investigated the covariations between a major component of climate, namely the El Niño Southern Oscillation (ENSO), and indicators of the impact of influenza, as measured by morbidity, excess mortality and viral subtypes col-
\end{abstract}

lected in France during the period 1971-2002. We show that both the circulating subtype and the magnitude of ENSO are associated with the impact of influenza epidemics. Recognition of this association could lead to better understanding of the mechanisms of emergence of influenza epidemics.

Key words: Climate, Disease outbreaks/statistics \& numerical data, Ecology, Environment, Influenza/ epidemiology, Influenza/morbidity, Influenza/mortality Abbreviations: ENSO - el ninõ southern oscillation; ILI - influenza-like-illnesses; M - million; MEI -
multivariate el ninõ southern oscillation index; P\&I - pneumonia and influenza

\section{Introduction}

Influenza epidemics affect human populations world wide, resulting in significant morbidity, mortality and economic burden. Overcrowding and disorganization of health care facilities are due, in part, to explosive outbreaks of unpredictable impact [1-3]. It is estimated that the disease is responsible for 50 million illnesses and up to 47,200 all-causes excess deaths in the United States alone each year [4-6], with similar figures in Europe [7-9].

Between two influenza pandemics, there is a frequent replacement of new viral strains that emerge and circulate globally [10]. The determinants of the emergence and diffusion of these strains are not well-understood [10]. The circulating (sub)type of influenza virus is recognized as a determinant of the epidemic impact [6]. Most importantly, the incidence of influenza displays a seasonal pattern in temperate zones of the world which mechanisms remain yet unexplained [11, 12]. Several authors have suggested the role of climate as a driving force of seasonality [13-15].

The El Niño Southern Oscillation (ENSO) represents the largest quasi-periodic signal in inter-annual climate variation, affecting global atmospheric and oceanic circulation patterns $[13,16]$. The ENSO phenomenon undergoes cycles between warm phases - extreme during El Niño episodes - and reverse cold phases - extreme during La Niña episodes. Several reports have determined that El Niño events are associated with infectious diseases [13, 17-21], including dengue fever [22, 23], Rift Valley fever [24], malaria [25-28], cholera [29-31], and diarrhoeal diseases [32], although the claimed links remain debated [33]. Recently an association of ENSO with hospitalization of women with viral pneumonia and influenza was evidenced in the region of Sacramento, California [14]. Here we examine the association between the impact of influenza epidemics as measured by morbidity and mortality indicators in France over the period 1971-2002, and ENSO oscillations, together with the contemporaneous prevailing circulating viral subtypes.

\section{Material and methods}

\section{Data}

We used the records of ENSO oscillations over 19712002 and two independent influenza datasets that quantified the impact of winter epidemics in France during the same period. 
The Multivariate El Ninõ Southern Oscillation monthly Index (MEI) is a measure of ENSO oscillations based on sea-level pressure, zonal and meridional components of the surface wind, sea surface and air temperature, and cloudiness fraction of the sky over the tropical Pacific [13]. The MEI is the unrotated first principal component of the six variables, where all values are standardized with respect to the 1950-1993 reference period - positive values indicate warm ENSO phases and negative values cold phases. The MEI is available on the internet from the National Oceanic and Atmospheric Administration, Climate Diagnosis Center: http://www.cdc.noaa.gov.

We studied influenza morbidity data collected by the French Sentinel Network, a computerized surveillance system of 1790 voluntary and unpaid general practitioners (GP) located throughout the entire country [34, 35]. Each GP reported on a weekly basis the number of consultations for 10 conditions, including Influenza-Like Illnesses (ILI), during 19842002. Spatial and temporal incidence series can be downloaded without access restriction on sentiweb: http://www.u444.jussieu.fr/sentiweb.

National mortality data collected from death certificates were used to assess the extent of influenzarelated mortality each winter in France during 19711997. All French death certificates are coded and computerized at a unique data center, the Institut National de la Santé et de la Recherche Médicale, Service Commun 8. We compiled the number of underlying pneumonia and influenza $(\mathrm{P} \& \mathrm{I})$ deaths, codes 470-474, 480-486 for the 8th revision and 480487 for the 9th revision of the International Classification of Deaths. Partial time series are available on the web: http://sc8.vesinet.inserm.fr: 1080.

The predominant viral circulating subtypes were determined for each influenza season by the two national influenza reference centres for France for 1984-2002 (Laboratoire de Virologie, Université Claude Bernard, Lyon; Institut Pasteur, Paris; per. commun.).

\section{Methods \\ Estimating the morbidity and mortality impact of influenza epidemics}

To define the morbidity impact of the 18 influenza epidemics spanning 1984-2002, a linear regression model was fitted to the weekly ILI incidence time series discarding weeks where influenza incidence exceeded 300 cases $/ 100,000$ population [36]. The model included a time trend and harmonic coefficients accounting for seasonality. The model yielded a baseline non-epidemic level as well as an epidemic threshold, determined by the upper limit of the $95 \%$ confidence interval. An epidemic was defined when the observed time series exceeded the threshold, but only if it exceeded the threshold for more than two consecutive weeks. The morbidity impact of an epidemic was the cumulative number of ILI cases during that epidemic.

A similar approach was used to define epidemic periods from the weekly P\&I mortality time series over the period 1971-1997. The mortality impact of an epidemic, or 'excess mortality', was the number of P\&I deaths exceeding the seasonal baseline during the epidemic [6].

\section{Modelling influenza impact with climate and viral factors}

To get an 'annualized' climate series, we averaged MEI values over the months of September to December preceding each influenza season. We then compared influenza morbidity and mortality impacts during cold and warm ENSO conditions, defined by resp. a negative and positive MEI average.

We tested the correlation between the morbidity impacts of the 18 influenza seasons under study (1984/85 to 2001/02) and the MEI annualized climate time series (September-December 1984 to September-December 2001). To derive a $p$-value for the correlation, we generated 1000 permutations of the morbidity impacts. We computed the correlation of the 1000 permuted impacts with the original climate series. This gave the distribution of correlation coefficients under the null hypothesis of no association (no correlation).

An observed (significant) correlation between influenza morbidity impact and climate could still be a spurious result due to auto-correlation in these series. We tested the hypothesis that the 18 epidemics displayed substantial auto-correlation in their morbidity impact, using the Kolmogoroff-Smirnov test described by Kulperger and Lockhart [37]. A p-value for the test was derived by generating 1000 artificial series by permutation of the morbidity impacts and calculating the test statistics on the permuted data. This gave the distribution of the test statistics under the null hypothesis of no auto-correlation.

Finally, since viral (sub)types are recognized as a cause of variability of the impact of influenza [6], we developed a linear regression 'base model' to explain influenza morbidity with the viral (sub)type of the circulating strain(s). In a second 'full model', we added climate as a covariate, following:

$$
\begin{aligned}
\text { Influenza morbidity impact } & =a+b * \text { strains }_{t} \\
& +c * \mathrm{MEI}_{t}+\varepsilon_{t}
\end{aligned}
$$

where impact $t_{t}$ is the influenza morbidity impact for epidemic $t(1984 / 85 \leq t \leq 2001 / 02)$; strains $_{t}$ is a class variable for the strain (sub)type(s) dominant in epidemic $t$ (that can take the value $\mathrm{A} / \mathrm{H} 1 \mathrm{~N} 1, \mathrm{~A} / \mathrm{H} 3 \mathrm{~N} 2$, $\mathrm{B}$ or any combination of the above); $\mathrm{MEI}_{t}$ is the climate index averaged over September to December 
preceding epidemic $t ; a, b$ and $c$ are regression coefficients to be estimated; and $\varepsilon_{t}$ is iid normally distributed with mean 0 and variance $\sigma$, independent with strains ${ }_{t}$ and $\mathrm{MEI}_{t}$. The improvement in fit of the full model against the base model was evaluated by bootstrap [38]. Using the base model, we generated 1000 artificial time series of influenza morbidity impacts by adding a vector of randomized observed residuals to the vector of predictions. Both the full and base models were then fitted to the artificial time series, and the difference in fit (measured by the difference in $r$-square, $r^{2}$ ) was used to illustrate an improvement solely due to the larger number of variables in the full model. The differences in $r^{2}$ in the artificial series were compared with the difference in $r^{2}$ in the original series to derive a $p$-value for the improvement in fit of the climate variable [31].

\section{Results}

For the 18 influenza seasons spanning 1984-2002, the morbidity impact of influenza averaged 2.9 million (M) cases per season ( $\sim 5 \%$ of the French population, $60 \mathrm{M}$ in 2002$)$, ranging from $0.7 \mathrm{M}(\sim 1 \%)$ to $4.8 \mathrm{M}$ $(\sim 8 \%)$. There was on average $3.7 \mathrm{M}$ cases during the 10 cold phases of ENSO vs. $1.8 \mathrm{M}$ cases during the 8 warm phases (Wilcoxon test, $p=0.001$, Figure 1a). The correlation between influenza morbidity and the MEI climate index was $0.65(p=0.012$, bootstrap test). We performed a sensitivity analysis to test various lags between the climate and the influenza morbidity series. The correlation was of the same order of magnitude when the climate series preceded by 0 to 6 months the morbidity series (correlation coefficient $>0.60$ ). The correlation declined monotonously down to negative values when the climate series preceded by more than 6 months, or followed, the morbidity series. No auto-correlation, which could have induced a spurious association, was detected in the 18 morbidity impacts ( $p=0.25$, Kolmogoroff-Smirnov test).

Influenza mortality impact, measured by $P \& I$ excess mortality over 26 winter seasons spanning 1971-1997, showed a similar pattern of association. On average in France, 2500 P\&I excess deaths occurred per season (range 0-9500). The mortality impact was significantly higher during the 10 seasons with cold ENSO conditions (mean \pm standard error, $3530 \pm 654$ P\&I excess deaths) than during the 16 seasons with warm ENSO $(1856 \pm 574$ P\&I excess deaths) (Wilcoxon test, $p=0.03$; Figure $1 b$ ).

The 'base model', explaining influenza morbidity impact over 1984-2002 with the dominant viral (sub)type only, accounted for $25 \%$ of the overall variance. The variance explained by the 'full model' including the MEI climate index increased to $61 \%$. The 1000 bootstrap simulations consistently showed improvement in fit by the MEI variable $(p=0.003)$, (a) INFLUENZA MORBIDITY IMPACT

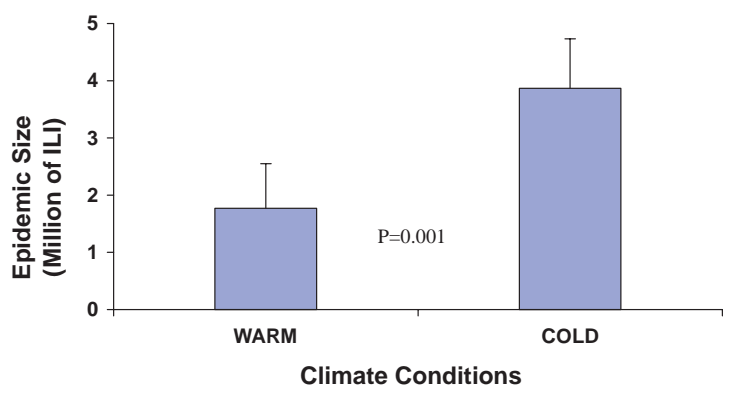

(b) INFLUENZA MORTALITY IMPACT

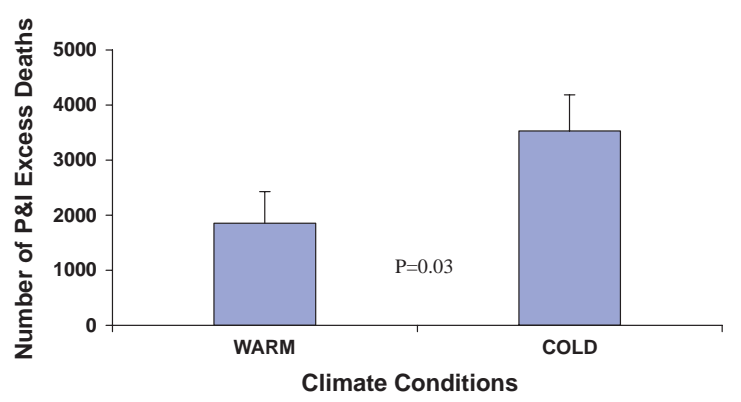

Figure 1. (a) Influenza morbidity and climate: Size of influenza-like-illness (ILI) winter epidemics (mean \pm standard error) during cold and warm climate conditions, 1984-2002, France. (b) Influenza mortality and climate: Pneumonia and influenza $(\mathrm{P} \& \mathrm{I})$ winter excess mortality (mean \pm standard error) during cold and warm climate conditions, 1971-1997, France. Cold (resp. warm) climate conditions are defined by a negative (resp. positive) multivariate El Niño Southern Oscillations Index averaged over September-December preceding an influenza epidemic.

indicative of a highly significant climate predictor. We computed the predicted $95 \%$ confidence intervals for the morbidity impact of the 18 influenza epidemics, as given by the full model. With this model, the observed morbidity impact fell in the expected confidence interval for 16 of the 18 epidemic seasons. Note that there was co-circulation of two or more influenza dominant (sub)types for 5 of the 18 winter seasons $(28 \%)$.

\section{Discussion and conclusion}

In this work, we found an association between the mortality and morbidity impact of influenza epidemics in France and a global climate index. This association is reinforced by the fact that it was retrieved in two markers of influenza activity collected independently. Previously, a separate analysis conducted in California, USA, also evidenced an association between ENSO oscillations and hospitalizations for influenza and viral pneumonia [14].

Although at present no biological mechanism is known to explain the role of climate variations in influenza epidemics, several arguments can be 
proposed. The emergence of new virus variants remains unclear [10] and may be influenced by ENSO oscillations. During the past inter-pandemic decade, new epidemic variants were often first isolated in China, which is considered as the influenza epicenter both in pandemic and inter-pandemic periods [10, 39]. Indeed, reports establish that ENSO conditions have a local effect over South-East Asia [13]. Moreover, changes in local conditions may affect respiratory virus survival and/or human indoor crowding and in turn alter the dynamics of virus transmission $[10,14,40]$. Strong cold ENSO phases have been associated with lower temperature and higher humidity in European winters [13], possibly promoting larger and more severe influenza epidemics in France.

\section{Acknowledgements}

We thank F. Carrat, K. Ebi, and M. Kitler for rewieving the manuscript. CV was supported by a grant from the French Ministère de l'Education Nationale et de la Recherche and from the Fondation pour la Recherche Médicale.

\section{References}

1. Dobson R. Flu rates in Wales highest for a decade. Br Med J 2000; 320: 138.

2. Christie B. Scotland facing worst flu outbreak for six years. Br Med J 2000; 320: 138.

3. Woodman R. Doctors and politicians clash over size of flu problem. Br Med J 2000; 320: 138.

4. Monto AS. Individual and community impact of influenza. Pharmacoeconomics 1999; 16: 1-6

5. Cox NJ, Subbarao K. Influenza. Lancet 1999; 354: 1277-1282.

6. Simonsen L, Clarke MJ, Williamson GD, Stroup DF, Arden NH, Schonberger LB. The impact of influenza epidemics on mortality: introducing a severity index. Am J Public Health 1997; 87: 1944-1950.

7. Carrat F, Valleron AJ. Influenza mortality among the elderly in France, 1980-90: How many deaths may have been avoided through vaccination? J Epidemiol Commun Health 1995; 49: 419-425.

8. Fleming DM, Zambon M, Bartelds AI, de Jong JC. The duration and magnitude of influenza epidemics: A study of surveillance data from sentinel general practices in England, Wales and The Netherlands. Eur J Epidemiol 1999; 15: 467-473.

9. Carrat F, Sahler C, Rogez S, et al. Influenza burden-ofillness: Estimates from a national prospective survey of household contacts in France. Arch Intern Med 2002; 162: $1842-1848$.

10. Cox NJ, Subbarao K. Global epidemiology of influenza: Past and present. Annu Rev Med 2000; 51: 407-421.

11. Thacker SB. The persistence of influenza A in human populations. Epidemiol Rev 1986; 8: 129-142.
12. Hope-Simpson RE. The role of season in the epidemiology of influenza. J Hyg (Lond) 1981; 86: 35-47.

13. Glantz MH. Currents of Change: Impacts of El Ninõ and La Ninã on Climate and Society, 2nd edn. Cambridge University Press, 2001.

14. Ebi KL, Exuzides KA, Lau E, Kelsh M, Barnston A. Association of normal weather periods and El Nino events with hospitalization for viral pneumonia in females: California, 1983-1998. Am J Public Health 2001;91:1200-1208.

15. Colwell RR, Patz JA. Climate, Infectious Disease and Health: An Interdisciplinary Perspective. Washington DC: American Academy of Microbiology, 1998.

16. Wang HJ, Zhang RH, Cole J, Chavez F. El Nino and the related phenomenon Southern Oscillation (ENSO): The largest signal in interannual climate variation. Proc Natl Acad Sci USA 1999; 96: 11071-11072.

17. Epstein PR, Calix Pena O, Blanco Racedo J. Climate and disease in Colombia. Lancet 1995; 346: 1243-1244.

18. Epstein PR. Global warming and vector-borne disease. Lancet 1998; 351: 1737; discussion 1738.

19. Bouma MJ, Sondorp HE, van der Kaay HJ. Health and climate change. Lancet 1994; 343: 302.

20. Bouma MJ, Kovats RS, Goubet SA, Cox JS, Haines A. Global assessment of El Nino's disaster burden. Lancet 1997; 350: 1435-1438.

21. Patz JA, Epstein PR, Burke TA, Balbus JM. Global climate change and emerging infectious diseases. JAMA 1996; 275: 217-223.

22. Hales S, Weinstein P, Woodward A. Dengue fever epidemics in the South Pacific: Driven by El Nino Southern Oscillation? Lancet 1996; 348: 1664-1665.

23. Hales S, Weinstein P, Souares Y, Woodward A. El Nino and the dynamics of vectorborne disease transmission. Environ Health Perspect 1999; 107: 99-102.

24. Linthicum KJ, Anyamba A, Tucker CJ, Kelley PW, Myers MF, Peters CJ. Climate and satellite indicators to forecast Rift Valley fever epidemics in Kenya. Science 1999; 285: 397-400.

25. Bouma MJ, van der Kaay HJ. Epidemic malaria in India and the El Nino southern oscillation. Lancet 1994; 344: 1638-1639.

26. Bouma MJ, Sondorp HE and van der Kaay HJ. Climate change and periodic epidemic malaria. Lancet 1994; 343: 1440.

27. Bouma MJ, Dye C, van der Kaay HJ. Falciparum malaria and climate change in the northwest frontier province of Pakistan. Am J Trop Med Hyg 1996; 55: 131-137.

28. Bouma MJ, Dye C. Cycles of malaria associated with El Ninõ in Venezuela. JAMA 1997; 278: 1772-1774.

29. Colwell RR. Global climate and infectious disease: The cholera paradigm. Science 1996; 274: 2025-2031.

30. Lobitz B, Beck L, Huq A, et al. From the cover: climate and infectious disease: Use of remote sensing for detection of Vibrio cholerae by indirect measurement. Proc Natl Acad Sci USA 2000; 97: 1438-1443.

31. Pascual M, Rodo X, Ellner SP, Colwell R, Bouma MJ. Cholera dynamics and El Nino-Southern Oscillation. Science 2000; 289: 1766-1769.

32. Checkley W, Epstein LD, Gilman RH, et al. Effects of el Ninõ and ambient temperature on hospital admissions for diarrhoeal diseases in Peruvian children. Lancet 2000; 355: 442-450. 
33. Hay SI, Myers MF, Burke DS, et al. Etiology of interepidemic periods of mosquito-borne disease. Proc Natl Acad Sci USA 2000; 97: 9335-9339.

34. Garnerin P, Saidi Y, Valleron AJ. The French Communicable Diseases Computer Network. A seven-year experiment. Ann N Y Acad Sci 1992; 670: 29-42.

35. Colin C, Geffroy L, Maisonneuve H, et al. Country profile. France. Lancet 1997; 349: 791-797.

36. Costagliola D, Flahault A, Galinec D, Garnerin P, Menares J, Valleron AJ. A routine tool for detection and assessment of epidemics of influenza-like syndromes in France. Am J Pub Health 1991; 81: 97-99.

37. Kulperger RA, Lockhart J. Tests of Independence in Time Series. J Time Ser Anal 1998; 19: 165.

38. Efron B, Tibshirani RJ. Introduction to the Bootstrap. Monograph on Statistics and Applied Probability. New York: CRC Press, 1993.
39. Shortridge KF. Is China an influenza epicentre? Chin Med J (Engl) 1997; 110: 637-641.

40. Hammond GW, Raddatz RL, Gelskey DE. Impact of atmospheric dispersion and transport of viral aerosols on the epidemiology of influenza. Rev Infect Dis 1989; 11: 494- 497 .

Address for correspondence: Cécile Viboud, Current address: Division of International Epidemiology and Population Studies, Fogarty International Center/ National Institutes of Health, 16 Center Drive, Bethesda, MD 20892, USA

Phone: + 1-301-496-2146; Fax: + 1-301-496-8496

E-mail: viboudc@mail.nih.gov 